\title{
Isothermal crystallization of poly(L-lactide) and poly(butylene adipate) crystalline/crystalline blends
}

\author{
Lifen Zhao, Junjun Kong, Xiujuan Tian, Jun Zhang and Shengxue Qin
}

The isothermal crystallization kinetics, morphology and melting behavior of poly(L-lactide) and poly(butylene adipate) (PLLA/ PBA) crystalline/crystalline blends were studied in the high- and low-temperature regions using differential scanning calorimetry (DSC) and polarized optical microscopy (POM). In the high-temperature region, the PLLA crystallized faster, and the blends had lower equilibrium melting temperatures than neat PLLA due to the high-mobility PBA chain. In the low-temperature region, the PBA crystallization rate was lower in the blends. Additionally, the polymorphic structures and crystallization morphologies of PBA were influenced by PLLA greatly. The PBA in the blends formed $\alpha$ and $\beta$ crystal structures, whereas neat PBA only formed $\alpha$ crystal structures. POM indicated that the neat PBA formed Maltese-cross spherulites across the studied temperature range. However, banded spherulites formed in the blend at 32 and $34{ }^{\circ} \mathrm{C}$.

Polymer Journal (2014) 46, 323-329; doi:10.1038/pj.2014.8; published online 19 March 2014

Keywords: crystallization kinetics; melting behavior; poly(butylene adipate); poly(L-lactide); polymorphism

\section{INTRODUCTION}

With increasing public awareness of the environmental hazards of polymer disposal, increasing attention has been given to biodegradable polymers in recent years. Of all biodegradable polymers, poly(Llactide) (PLLA) stands out because it is biocompatible and non-toxic to both the environment and the humans. However, its slow crystallization rate, low crystallinity and inherent brittleness limit its applications in many fields. ${ }^{1,2}$

Blending PLLA with biodegradable polymers is a useful, economical way to improve its properties while maintaining its biodegradability. Many biodegradable aliphatic polyesters, such as poly(butylene succinate $),{ }^{3} \operatorname{poly}(\varepsilon$-caprolactone $),{ }^{4}$ poly $(3 \text {-hydroxybutyrate })^{5}$ and poly(ethylene oxide), ${ }^{6}$ have been blended with PLLA. An important feature of these aliphatic polyesters is their crystallinity. Therefore, these PLLA blends form crystalline/crystalline systems that can exhibit varying crystallization behaviors in complicated crystallization environments. Thus, the crystalline/crystalline blends not only improve the material usability but also supply many interesting samples that can be used to investigate crystallization behavior. Many works have been published on the miscibility, morphology, crystallization kinetics and melting behavior of PLLA blends, such as poly(butylene succinate)/PLLA, ${ }^{3}$ poly(3-hydroxybutyrate)/ poly(L-lactic acid $)^{5}$ and poly(ethylene succinate)/PLLA.6,7 The morphologies of the crystalline/crystalline blends have been shown to be influenced by the miscibility, crystallization process and unique morphologies that are occasionally formed. ${ }^{8-15}$ Furthermore, the kinetics and melting behavior were also altered by varying crystalline environments. ${ }^{7,8,11,15}$ These results provide many new choices that can be used to modify the material properties. Thus, the crystalline behavior of the crystalline/crystalline blends is worth studying from both the academic and industrial viewpoints.

Poly(butylene adipate) (PBA) is a biodegradable aliphatic polyester with abundant crystallization phenomena, such as complex crystalline morphologies, ${ }^{16}$ multiple melting behaviors and polymorphism. ${ }^{17,18}$ PBA was shown to improve the mechanical properties of PLLA. ${ }^{19}$ Thus, PLLA/PBA crystalline/crystalline blends are a valuable system for investigating polymer crystallization behavior. Furthermore, the melting points of PLLA and PBA greatly differ; the melting temperature of PLLA is $\sim 160^{\circ} \mathrm{C}$, while the melting temperature of PBA is below $75^{\circ} \mathrm{C}$. Therefore, their crystallization processes can be studied separately by controlling the temperature. Previously, we investigated the miscibility and morphologies of PLLA/PBA blends in high- and low-temperature regions. These blends were partially miscible and showed various crystallization morphologies. ${ }^{20}$ However, understanding the isothermal crystallization behaviors of these blends is important to obtain PLLA/PBA blends with desirable properties, which can allow us to design material with proper crystallinity and structures.

Therefore, the present work aims to clarify the interactions between PBA and PLLA by investigating their isothermal crystallization kinetics, melting behavior and crystallization morphologies in different temperature regions. The isothermal crystallization kinetics and melting behavior of the PLLA/PBA blends in the high- and lowtemperature regions were studied using differential scanning 
calorimeter (DSC). The polymorphism structures of the PLLA/PBA blends formed in the low-temperature regions were studied by combining the DSC and wide-angle X-ray diffractometer (WAXD) results. Additionally, the morphology of the blends formed at various temperatures was studied via polarized optical microscope (POM). The obtained results could be helpful for future PLLA/PBA blend applications and for studying the isothermal crystallization and melting behaviors of other polymer blends.

\section{EXPERIMENTAL PROCEDURE}

\section{Materials}

PLLA with $\mathrm{Mw}=250000 \mathrm{Da}$ was purchased from Nature Works (Blair, NE, USA). PBA with $\mathrm{Mw}=68000 \mathrm{Da}$ was synthesized via the melt polycondensation of 1,4-butanediol (CAS No 110-63-4, supplied by BASF, Ludwigshafen, Germany) and adipic acid (CAS No 124-04-9, supplied by BASF), with tetrabutyl orthotitanate (CAS No 5593-70-4, supplied by Fluka, Zurich, Switzerland) as the catalyst. ${ }^{21}$ The material was purified before use via solution depositing. PLLA and PBA were dissolved in tetrahydrofuran before precipitation from methanol and were dried under vacuum before the investigation.

\section{Blend preparation}

The PLLA/PBA blend samples were prepared using the mutual solvent tetrahydrofuran. A total of $10 \mathrm{mg}$ of the polymers (PLLA and PBA) were dissolved in $1 \mathrm{ml}$ of solvent and stirred in a flask. According to the research objectives, the blends were prepared with different compositions. To study the influence of PBA on PLLA crystallization, PLLA/PBA blends with 100/0 and 80/20 weight ratios were prepared. Similarly, to study the effects of PLLA on PBA crystallization behavior, PLLA/PBA blends with the 0/100 and 20/80 weight ratios were prepared. The blend solutions were first cast onto a Petri dish at room temperature. After evaporating the solvent under a controlled stream of air for 3 days, the blend was further dried in a vacuum at $40{ }^{\circ} \mathrm{C}$ for $72 \mathrm{~h}$ to remove the residual solvent. Cast films were prepared from PLLA/PBA blends with various compositions.

\section{Polarized optical microscopy}

The samples used to study the formed morphology via POM were prepared by casting blend solutions on covered glass $(20 \times 20 \mathrm{~mm}$ in size $)$. After volatilizing the solvent, the samples were melted on a hot stage at $200^{\circ} \mathrm{C}$ for $3 \mathrm{~min}$ before being transferred to a hot stage at a specific temperature for isothermal crystallization. After a sufficient time, POM pictures of the samples were taken at room temperature using a polarized optical microscope (Nikon Optiphot-2, POM, Nikon, Tokyo, Japan) equipped with a charge-coupled device digital camera.

\section{Differential scanning calorimetry}

The isothermal crystallization and thermal behavior of the PLLA/PBA blends were determined using a Mettler-Toledo DSC (DSC1, Zurich, Switzerland) operating under a nitrogen flow of $20 \mathrm{ml}$ per minute. The temperature and heat flow of the instrument were carefully calibrated using standard materials before measurements were taken. Samples of $\sim 3-5 \mathrm{mg}$ were encapsulated in the DSC aluminum pan.

Because the PLLA melt crystallization rate is very slow, an isothermal coldcrystallization procedure was adopted for this work. Therefore, the PLLA/PBA samples with weight ratios of $100 / 0$ and $80 / 20$ were first heated to $200{ }^{\circ} \mathrm{C}$ for $3 \mathrm{~min}$ and then cooled at a rate of $80^{\circ} \mathrm{C}$ per minute to a final temperature of $25^{\circ} \mathrm{C}$ for their isothermal crystallization. After $3 \mathrm{~min}$, the samples were heated to a given temperature, $T_{\mathfrak{c}}$, at a rate of $80^{\circ} \mathrm{C}$ per minute to finish the isothermal cold-crystallization. After sufficient time passed, the PLLA/PBA blends were heated directly from $T_{\mathrm{c}}$ to the melting point at a rate of $10^{\circ} \mathrm{C}$ per minute.

Because the PBA crystallizes rapidly, the isothermal crystallization in the low-temperature region was set as an isothermal melt-crystallization. The PLLA/PBA samples with a weight ratio of 0/100 and 20/80 were first heated to $200^{\circ} \mathrm{C}$ for $3 \mathrm{~min}$ for their isothermal crystallization before cooling at $80^{\circ} \mathrm{C}$ per minute to a given temperature, $T_{\mathfrak{c}}$, to finish the isothermal melt-crystallization. After sufficient time had passed, the PLLA/PBA blends were heated directly from $75^{\circ} \mathrm{C}$ to the melting point at a rate of $10{ }^{\circ} \mathrm{C}$ per minute.

\section{Wide-angle X-ray diffraction}

To investigate the polymorphism structures of PBA, PLLA/PBA films with a weight ratio of $0 / 100$ and $20 / 80$ were prepared by first sandwiching the polymer samples between two poly(ethylene terephthalate) sheets, with another poly(ethylene terephthalate) film $(0.1 \mathrm{~mm}$ in thickness) as a spacer; the samples were then compressed on a hot plate at $200^{\circ} \mathrm{C}$ for $2 \mathrm{~min}$ at a pressure of $15 \mathrm{MPa}$. Afterwards, the sandwiched polymer films were rapidly transferred to an oven at the temperature designated for isothermal crystallization. After the complete crystallization, the polymer films were separated for wide-angle X-ray diffraction analysis. The WAXD patterns were recorded at room temperature on a Rigaku D/Max-2500PC diffractometer (Nagano, Japan) using nickel-filtered $\mathrm{Cu} \mathrm{K} \alpha$ radiation (wavelength $\lambda=0.154 \mathrm{~nm}, 40 \mathrm{kv}$ and $110 \mathrm{~mA}$ ) across the $2 \theta$ range from $6^{\circ}$ to $40^{\circ}$, with a scanning step of $0.02^{\circ}$.

\section{RESULTS AND DISCUSSION}

Isothermal crystallization of neat PLLA and PLLA/PBA blends in the high-temperature region

The neat PLLA and PLLA/PBA blend with an 80/20 weight ratio were used to investigate the effects that incorporating PBA had on PLLA crystallization. The isothermal cold crystallization kinetics were first studied in the temperature region from $95^{\circ} \mathrm{C}$ to $110^{\circ} \mathrm{C}$ using the Avrami equation: $:^{22,23}$

$$
1-X_{t}=\exp \left(-k t^{n}\right)
$$

where $X_{t}$ is the relative crystallinity, $k$ is the crystallization rate constant associated with nucleation and growth processes and $n$ is the Avrami index, which depends on the nucleation nature and crysta growth spatial dimensions. Figure 1 shows the relative crystallinity $\left(X_{t}\right)$ curves versus the crystallization time for neat PLLA and the PLLA/PBA blend. The observed crystallization time for each sample shortened with increasing crystallization temperature. The blend crystallization time was shorter than that of neat PLLA at the same temperature. For example, neat PLLA requires $\sim 80 \mathrm{~min}$ to finish the crystallization process at $95^{\circ} \mathrm{C}$, while the PLLA/PBA blend requires $\sim 50 \mathrm{~min}$

Avrami plots are shown in Figure 2 to compare the isothermal crystallization of neat PLLA with PLLA/PBA in detail. The parameters $K$ and $n$ were separately obtained from interceptions and the slopes of the plots. The parameter $t_{0.5}$ was calculated according to equation (2). All the parameters including $K, n$ and $t_{0.5}$ are listed in Table 1 .

$$
t_{0.5}=\left(\frac{\ln 2}{k}\right)^{1 / n}
$$

The values of $n$ for both the neat PLLA and PLLA/PBA blends were between 2.2 and 2.7, which is close to 3 . These results indicate that the PLLA crystal grows in three dimensions. Additionally, incorporating PBA did not change the crystallization mechanism of PLLA.

On the basis of the $t_{0.5}$ value, the crystallization rate varied greatly with the crystallization temperature. For neat PLLA and PLLA/ $\operatorname{PBA}(80 / 20)$, the crystallization rate increased with increasing crystallization temperature across the range from 95 to $110^{\circ} \mathrm{C}$. This trend was because the mobility of the molecular chain improved with the increasing crystallization temperature. Comparing the $t_{0.5}$ values for the blended and neat PLLA indicated that the PLLA/PBA blend had a faster crystallization rate than the neat PLLA. As we previously reported, ${ }^{20}$ PBA has two effects on PLLA crystallization. On one hand, PBA has a diluting effect on PLLA, which reduces the nucleation density. On the other hand, it promotes PLLA mobility and improves the growth rate after nucleation. The combined results 
a
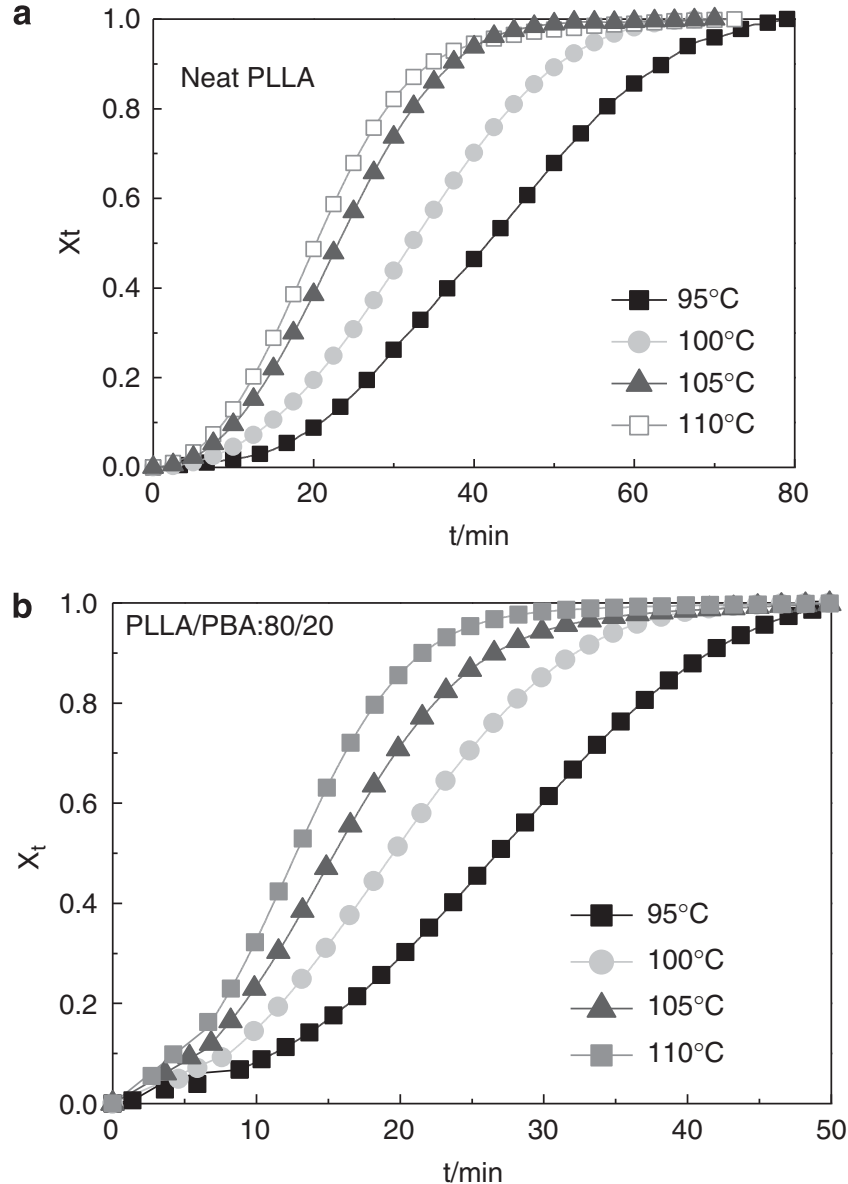

Figure 1 Plots of the relative crystallinity degree versus the crystallization temperature. (a) Neat PLLA and (b) PLLA/PBA 80/20. A full color version of this figure is available at Polymer Journal online.

in Table 1 indicate that the second effect is stronger in the PLLA/PBA blend, and PBA loading increases the PLLA crystallization rate.

Figure 3 shows the DSC heating curves after isothermal crystallization for both neat PLLA and PLLA/PBA(80/20). Both the neat PLLA and the PLLA/PBA blend contained two melting peaks: $T_{\mathrm{m} 1}$ in the low-temperature region and $T_{\mathrm{m} 2}$ in the high-temperature region. The endothermic peak temperatures for $T_{\mathrm{m} 1}$ and $T_{\mathrm{m} 2}$ as a function of $T_{\mathrm{c}}$ are shown in Figure 4. The location of $T_{\mathrm{m} 2}$ is independent of the crystallization temperature, and its intensity decreased with increasing $T_{\mathrm{c}}$, while $T_{\mathrm{m} 1}$ strictly depended on the crystallization temperature.

Therefore, the equilibrium melting temperature $\left(T_{\mathrm{m}}{ }^{0}\right)$ can be obtained from the primary crystallization melting peak and crystallization temperature using Hoffman-Weeks's equation: ${ }^{24}$

$$
T_{\mathrm{m}}=T_{\mathrm{m}}^{0}\left(1-\frac{1}{r}\right)+\frac{T_{\mathrm{c}}}{r}
$$

where $r$ is a factor dependent on the lamellar thickness. Thus, the equilibrium melting temperature is $163{ }^{\circ} \mathrm{C}$ for PLLA and $162^{\circ} \mathrm{C}$ for PLLA/PBA. The $T_{\mathrm{m}}^{0}$ values were obvious lower than those reported in the literature $\left(206.8^{\circ} \mathrm{C}\right) .^{25}$ This difference is because a commercial PLLA sample was used in this work, and this sample was not $100 \%$ pure PLLA. However, the decrease in the equilibrium melting temperature is very small (only $1{ }^{\circ} \mathrm{C}$ ) for the PLLA/PBA blends, which indicates that the addition of PBA had little effect on the PLLA lamella thickness in the blends.
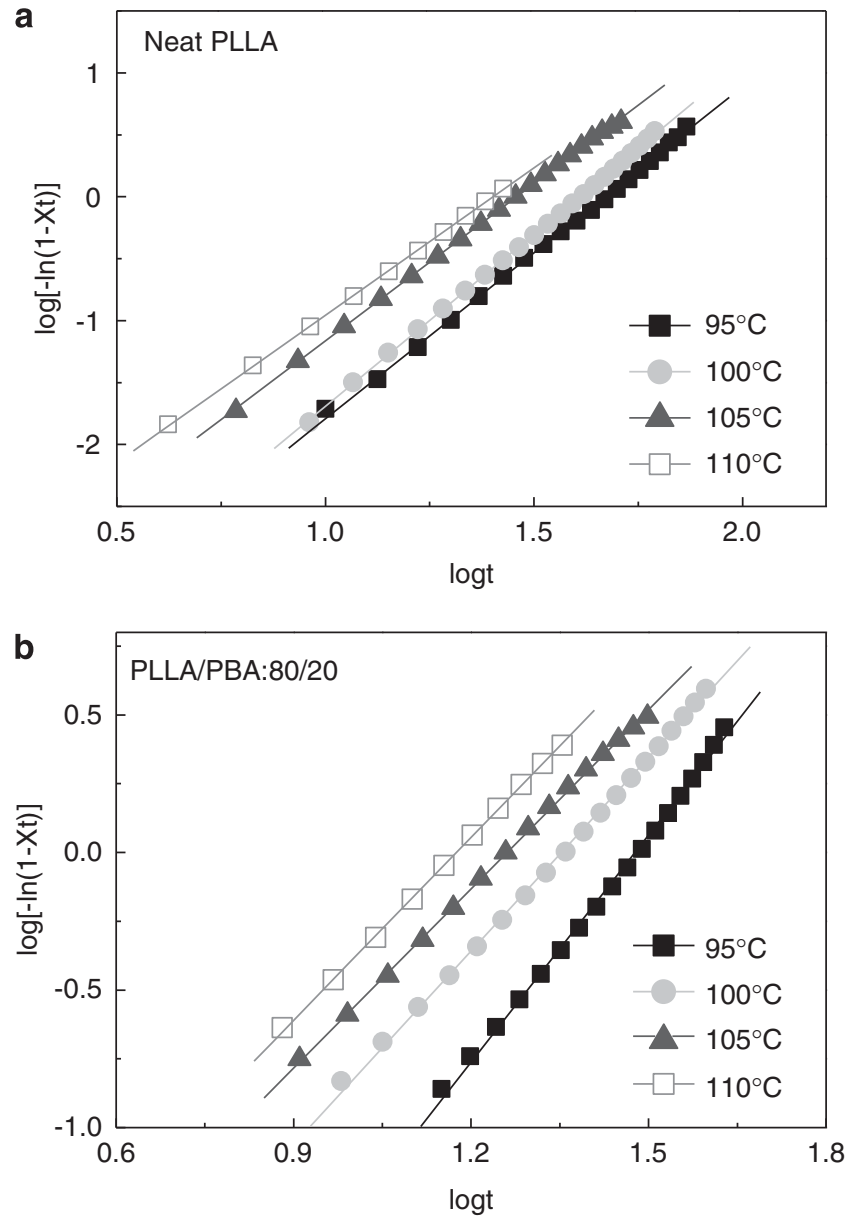

Figure 2 Avrami plots for (a) neat PLLA and (b) PLLA/PBA 80/20. A full color version of this figure is available at Polymer Journal online.

Table 1 Isothermal crystallization kinetics parameters of neat PLLA and PLLA/PBA blend obtained by Avrami fit

\begin{tabular}{lrccc}
\hline Samples & $T_{c}\left({ }^{\circ} \mathrm{C}\right)$ & $\mathrm{N}$ & $K\left(\mathrm{~min}^{-n}\right)$ & $t_{0.5}(\mathrm{~min})$ \\
\hline Neat PLLA & 95 & 2.7 & $3.3 \times 10^{-5}$ & 40.7 \\
& 100 & 2.8 & $3.2 \times 10^{-5}$ & 35.7 \\
& 105 & 2.6 & $1.8 \times 10^{-4}$ & 24.9 \\
PLLA/PBA:80/20 & 110 & 2.4 & $4.5 \times 10^{-4}$ & 21.6 \\
& 95 & 2.8 & $8.6 \times 10^{-5}$ & 26.2 \\
& 100 & 2.4 & $5.2 \times 10^{-3}$ & 19.1 \\
& 105 & 2.2 & $1.9 \times 10^{-3}$ & 15.4 \\
& 110 & 2.2 & $2.4 \times 10^{-3}$ & 12.7 \\
\hline
\end{tabular}

Abbreviations: PBA, poly(butylene adipate); PLLA, poly(L-lactide).

Figure 5 shows the POM images for the neat PLLA and PLLA/PBA 80/20 after a sufficient isothermal crystallization time at different temperatures. Both the neat PLLA and the PLLA/PBA blend formed Maltese-cross spherulites. However, the spherulite diameter of the blend was notably larger than the neat PLLA at the same isothermal crystallization temperatures. For example, the neat PLLA spherulite diameter at $100^{\circ} \mathrm{C}$ was $\sim 7 \mu \mathrm{m}$, while that of the PLLA/PBA blend was $\sim 13 \mu \mathrm{m}$. Because PBA has a diluting effect on PLLA, the PLLA nuclei density decreased. Additionally, incorporation of low viscosity PBA also promoted the mobility of the PLLA molecular chain and 

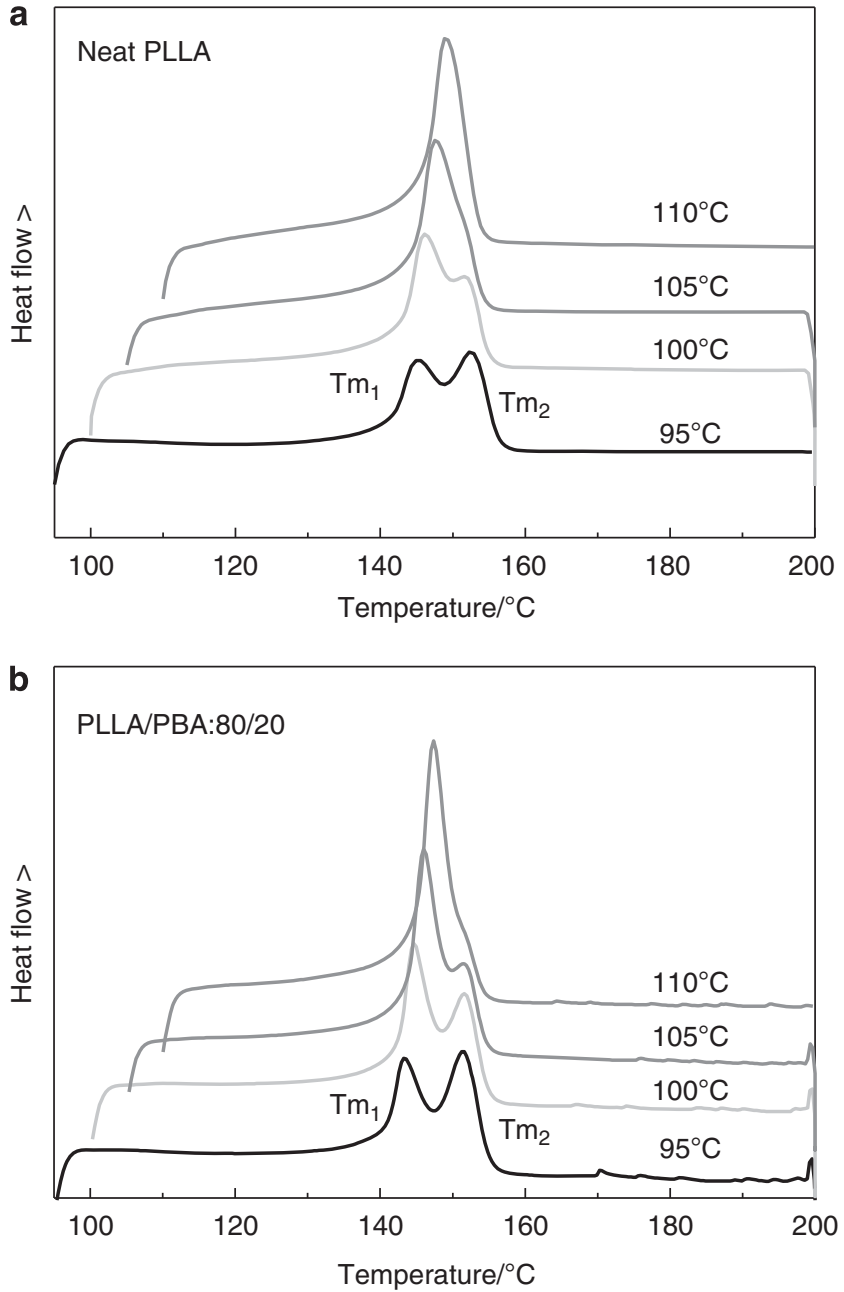

Figure 3 DSC melting curves after isothermal crystallization at different temperatures using a heating rate of $10^{\circ} \mathrm{C}$ per minute. (a) Neat PLLA and (b) PLLA/PBA 80/20. A full color version of this figure is available at Polymer Journal online.

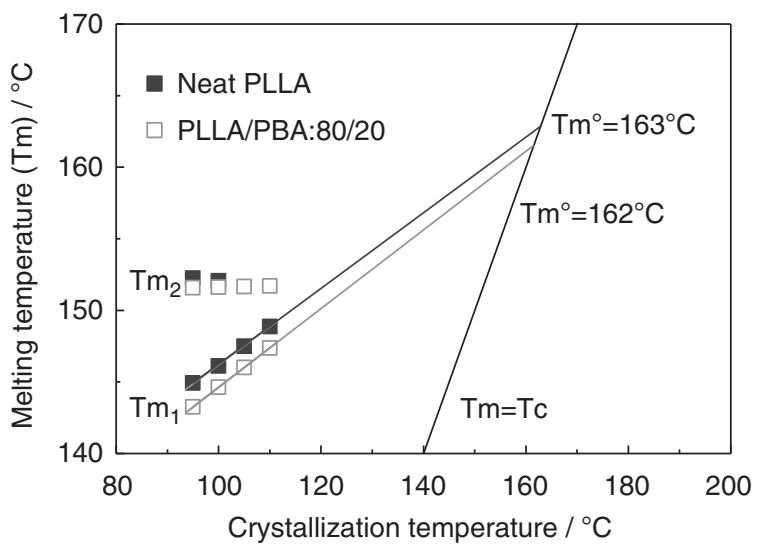

Figure 4 Melting points for neat PLLA and PLLA/PBA 80/20 as a function of the crystallization temperature. A full color version of this figure is available at Polymer Journal online.
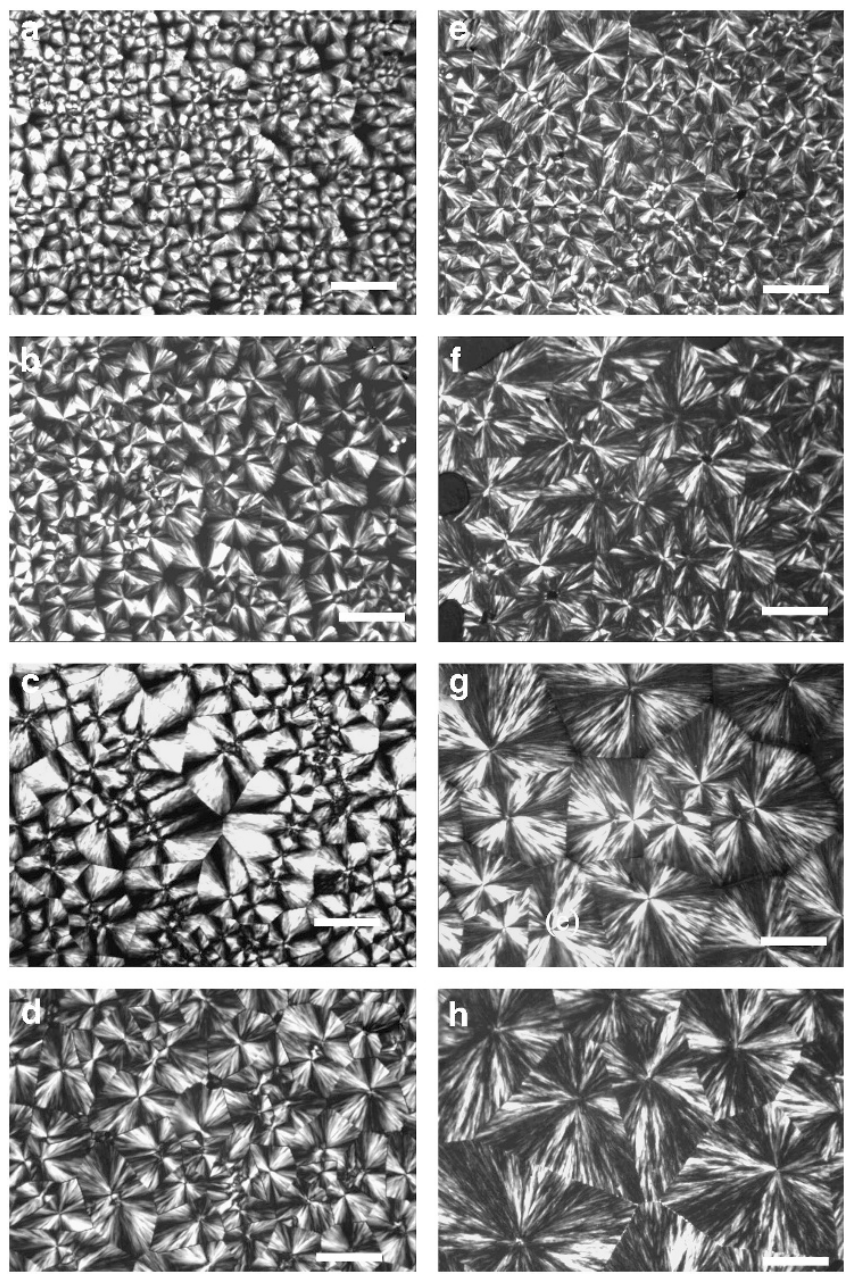

Figure 5 Polarized optical micrographs for neat PLLA and PLLA/PBA 80/20 morphologies formed at different temperatures. The left column shows images for neat PLLA: (a) $95^{\circ} \mathrm{C}$, (b) $100^{\circ} \mathrm{C}$, (c) $105^{\circ} \mathrm{C}$ and (d) $110^{\circ} \mathrm{C}$. The right column shows images for PLLA/PBA 80/20: (e) $95^{\circ} \mathrm{C}$, (f) $100^{\circ} \mathrm{C}$ (g) $105^{\circ} \mathrm{C}$ and (h) $110^{\circ} \mathrm{C}$. The scale bar is $10 \mu \mathrm{m}$.

improved the spherulite growth rate. Therefore, the number of spherulites in the blend was lower than the PLLA under identical conditions, and the blend spherulite diameter was larger than the neat PLLA. The same phenomena have been observed for many crystalline/crystalline blends, such as poly(butylene succinate)/ $\mathrm{PBA},{ }_{14}$ polyhydroxybutyrate (PHB)/atactic R,S-PHB-OH ${ }^{26}$ and poly(lactic acid)/poly( $\varepsilon$-caprolactone). ${ }^{27}$ The difference in spherulite diameter between the neat and blended PLLA also suggests that the incorporation of PBA promotes PLLA molecular chain mobility.

Isothermal crystallization of neat PBA and PLLA/PBA blends in the low-temperature region

Neat PBA and the PLLA/PBA blend with a weight ratio of 20/80 were used to investigate the effects that the incorporation of PLLA has on PBA crystallization. The isothermal crystallization and melting behavior in the temperature region from 32 to $38^{\circ} \mathrm{C}$ were investigated by DSC.

Figure 6 plots the relative crystallinity $(X t)$ versus the crystallization time for neat PBA and the PLLA/PBA blend. Using equation (1), the crystallization parameters, $k, n$ and $t_{0.5}$, were determined and are listed in Table 2. The $n$ value for the neat PBA is $\sim 4$, which suggests 


\section{a}

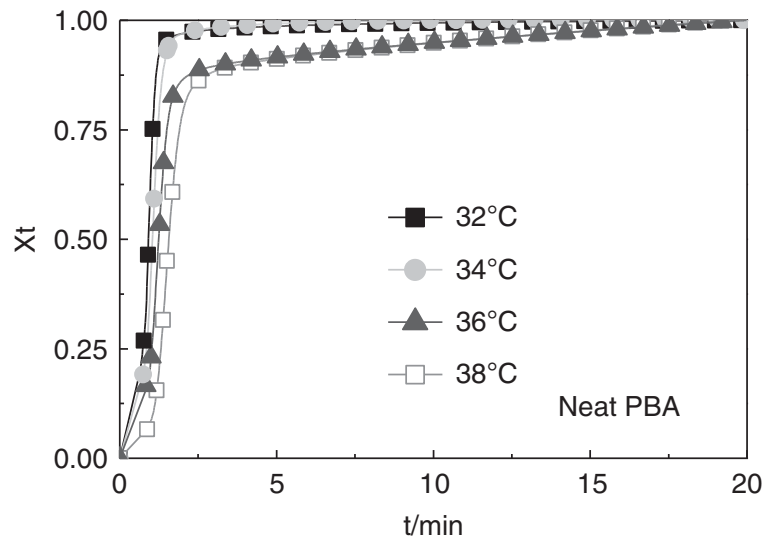

b

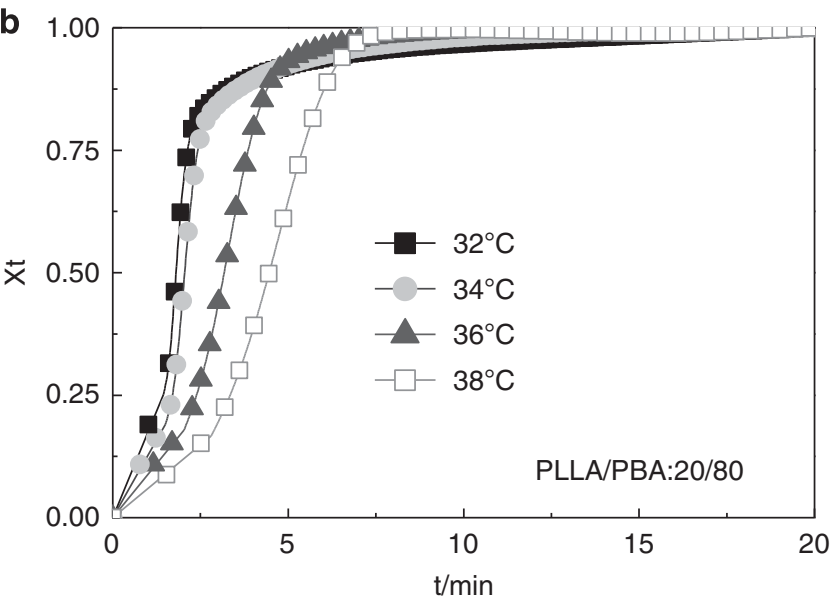

Figure 6 Plots of the relative crystallinity degree versus crystallization temperature. (a) Neat PBA and (b) PLLA/PBA 20/80. A full color version of this figure is available at Polymer Journal online.

Table 2 Isothermal crystallization kinetics parameters of neat PBA and PLLA/PBA blend obtained by Avrami fit

\begin{tabular}{lcccc}
\hline Samples & $T_{C}\left({ }^{\circ} \mathrm{C}\right)$ & $\mathrm{n}$ & $K\left(\mathrm{~min}^{-n}\right)$ & $t_{0.5}(\mathrm{~min})$ \\
\hline Neat PBA & 32 & 4.2 & 1.03 & 0.91 \\
& 34 & 4.1 & 0.59 & 1.04 \\
& 36 & 4.1 & 0.24 & 1.28 \\
PLLA/PBA:20/80 & 38 & 4.1 & 0.10 & 1.61 \\
& 32 & 4.3 & $5.3 \times 10^{-2}$ & 1.81 \\
& 34 & 4.1 & $3.2 \times 10^{-2}$ & 2.10 \\
& 36 & 3.2 & $1.8 \times 10^{-2}$ & 3.13 \\
& 38 & 3.4 & $4.8 \times 10^{-3}$ & 4.37 \\
\hline
\end{tabular}

Abbreviations: PBA, poly(butylene adipate); PLLA, poly(L-lactide).

that the crystals grow three-dimensionally in a homogenous mode. For the PLLA/PBA blend, the $n$ value varied from 3.2 to 4.3 , which is close to 4. This result indicates that the blend had the same crystallization mechanism as the neat PBA.

On the basis of the $t_{0.5}$ value, the crystallization rate decreased with increasing crystallization temperature for both the neat PBA and PLLA/PBA blends. However, the blend crystallization rate was notably slower than that of neat PBA based on the $t_{0.5}$ values of the two samples. This trend was because PLLA is in a
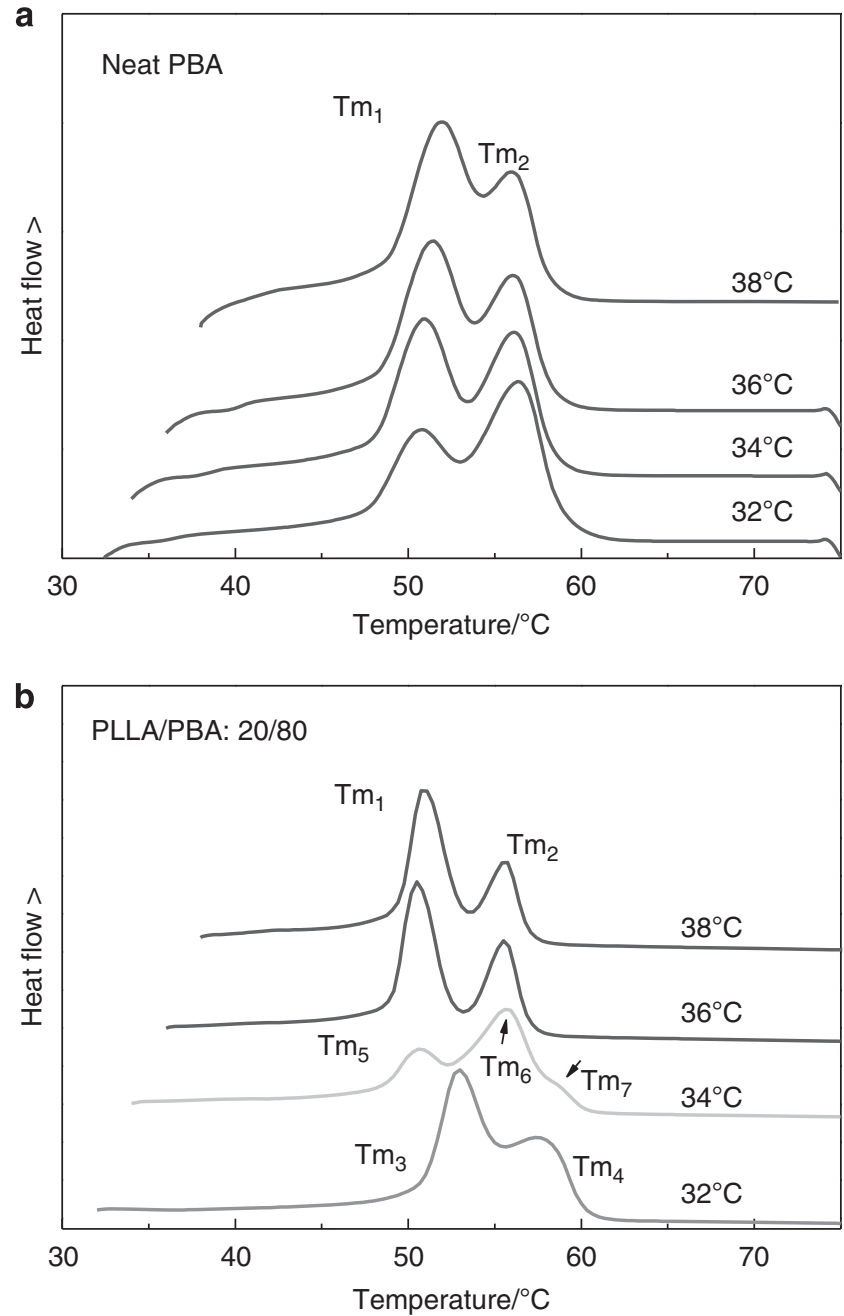

Figure 7 DSC melting curves after isothermal crystallization at different temperatures using a rate of $10^{\circ} \mathrm{C}$ per minute. (a) Neat PBA and (b) PLLA/ PBA 20/80. A full color version of this figure is available at Polymer Journal online.

glass state in this temperature region, and solid PLLA limits the mobility of the PBA molecular chain, which decreases the crystallization rate.

PBA contains polymorphic structures, and its melting behavior is very complex. Figure 7 shows the melting curves for neat PBA and the PLLA/PBA blend after their isothermal crystallization in the temperature region from 32 to $38^{\circ} \mathrm{C}$. Figure $7 \mathrm{a}$ indicates that neat PBA has two melting peaks: $T_{\mathrm{m} 1}$ and $T_{\mathrm{m} 2}$. As reported in Gan's work, ${ }^{18}$ neat PBA forms $\alpha$ crystals in this temperature range. $T_{\mathrm{m} 1}$ is the original melting point, whereas $T_{\mathrm{m} 2}$ is the melting point for the recrystallized $\alpha$ crystals.

The PLLA/PBA blend melting behavior significantly differed from the neat PBA (seen Figure 7b). For the temperature region from 36 to $38^{\circ} \mathrm{C}$, the blend had two melting peaks, $T_{\mathrm{m} 1}$ and $T_{\mathrm{m} 2}$. However, at $32^{\circ} \mathrm{C}$, the blends had two different peaks $\left(T_{\mathrm{m} 3}\right.$ and $\left.T_{\mathrm{m} 4}\right)$ than those observed for 36 and $38^{\circ} \mathrm{C}$. Moreover, at $34^{\circ} \mathrm{C}$, the blend exhibited three melting peaks. This type of multiple melting behavior is similar to the melting of neat PBA polymorphic crystals. ${ }^{18}$ Therefore, the PLLA/PBA blend may have formed polymorphic structures in the temperature region from 32 to $38^{\circ} \mathrm{C}$. 

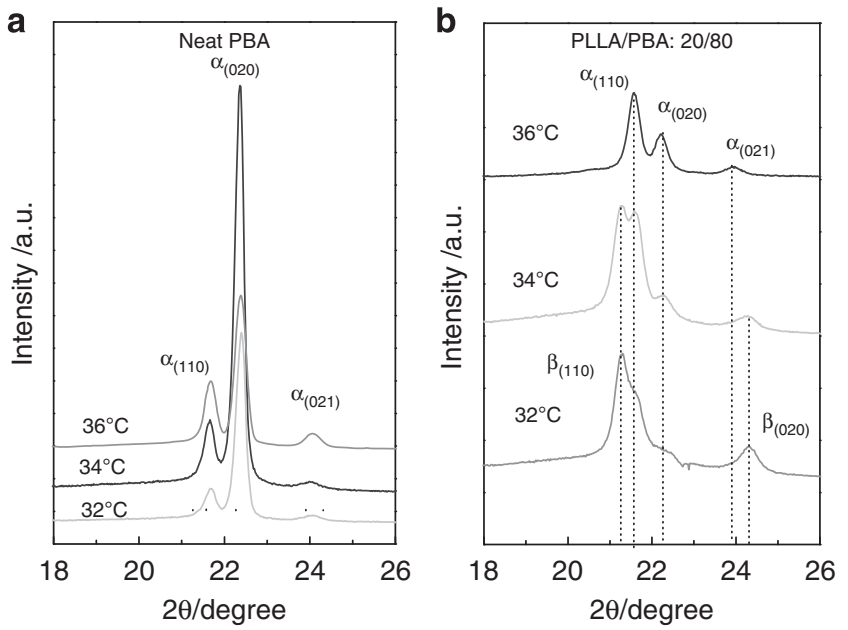

Figure 8 WAXD patterns for PLLA/PBA 20/80 films after isothermal crystallization at different temperatures. (a) Neat PBA and (b) PLLA/PBA 20/80. A full color version of this figure is available at Polymer Journal online.

WAXD was used to investigate the structures of the neat PBA and PLLA/PBA blend crystals formed at 32,34 and $36^{\circ} \mathrm{C}$ (seen in Figure 8). The neat PBA sample exhibited three diffraction peaks $\left(\alpha_{(110 /}, \alpha_{(020)}\right.$ and $\left.\alpha_{(021)}\right)$. These results suggest that PBA only forms $\alpha$ crystals in this temperature region, which is in agreement with the literature.${ }^{17}$ However, the diffractions peaks for the PLLA/PBA blend differ from those of neat PBA. At $36^{\circ} \mathrm{C}$, three diffraction peaks $\left(\alpha_{(110)}\right.$, $\alpha_{(020)}$ and $\left.\alpha_{(021)}\right)$ ascribed to an $\alpha$ crystal were observed. At $32^{\circ} \mathrm{C}$, two apparently new peaks $\left(\beta_{(110)}\right.$ and $\left.\beta_{(020)}\right)$ formed in positions different from those observed at $36^{\circ} \mathrm{C}$. Furthermore, at $34^{\circ} \mathrm{C}$, all of the $\alpha$ and $\beta$ crystal peaks can be observed. Thus, the PLLA/PBA blend was determined to form polymorphic PBA crystals in the temperature range from 32 to $38^{\circ} \mathrm{C}$.

The PBA crystal structure is very sensitive to temperature changes. ${ }^{18}$ In neat PBA, the thermodynamically stable $\alpha$ crystal forms above $32^{\circ} \mathrm{C}$, and the metastable $\beta$ crystal forms below $28^{\circ} \mathrm{C}$. For temperatures between 29 and $32^{\circ} \mathrm{C}$, PBA forms mixed $\alpha$ and $\beta$ crystals. However, in the PLLA/PBA blend, the $\beta$ and mixed crystals formed at 32 and $34^{\circ} \mathrm{C}$, respectively. Therefore, the addition of PLLA favored $\beta$ crystal formation. This $\beta$ crystal formation is related to dynamics and is kinetically preferred. ${ }^{18}$ The PBA crystallization rate in the PLLA/PBA blend decreased, as shown in Table 2. Accordingly, the very slow crystallization rate of the PLLA/PBA blend at $32{ }^{\circ} \mathrm{C}$ made the formation of the thermodynamic stable $\alpha$ crystal difficult. Thus, the metastable $\beta$ crystal, which has a fast crystallization rate, formed. Increasing the temperature $\left(34^{\circ} \mathrm{C}\right.$ or above) also increased the crystallization rate. The thermodynamically stable $\alpha$ crystal, which has a lower crystallization rate than the $\beta$ crystal, could then form. These results are in agreement with our previous work, which showed that the PBA $\alpha$ crystal easily forms when the PBA crystallization rate increases owing to the addition of the nucleating agent multimethylbenzilidene sorbitol (TM6). ${ }^{28}$

Figure 9 shows the POM pictures of the neat PBA and PLLA/PBA blend formed in the temperature region from 32 to $38^{\circ} \mathrm{C}$. Both PBA and PLLA/PBA formed spherulites whose diameters increased with increasing crystallization temperature. However, the PLLA/PBA blend formed banded spherulites at temperatures from 32 to $34{ }^{\circ} \mathrm{C}$, while neat PBA formed Maltese-cross spherulites across this range. The banded spherulite morphology of neat PBA is a consequence of
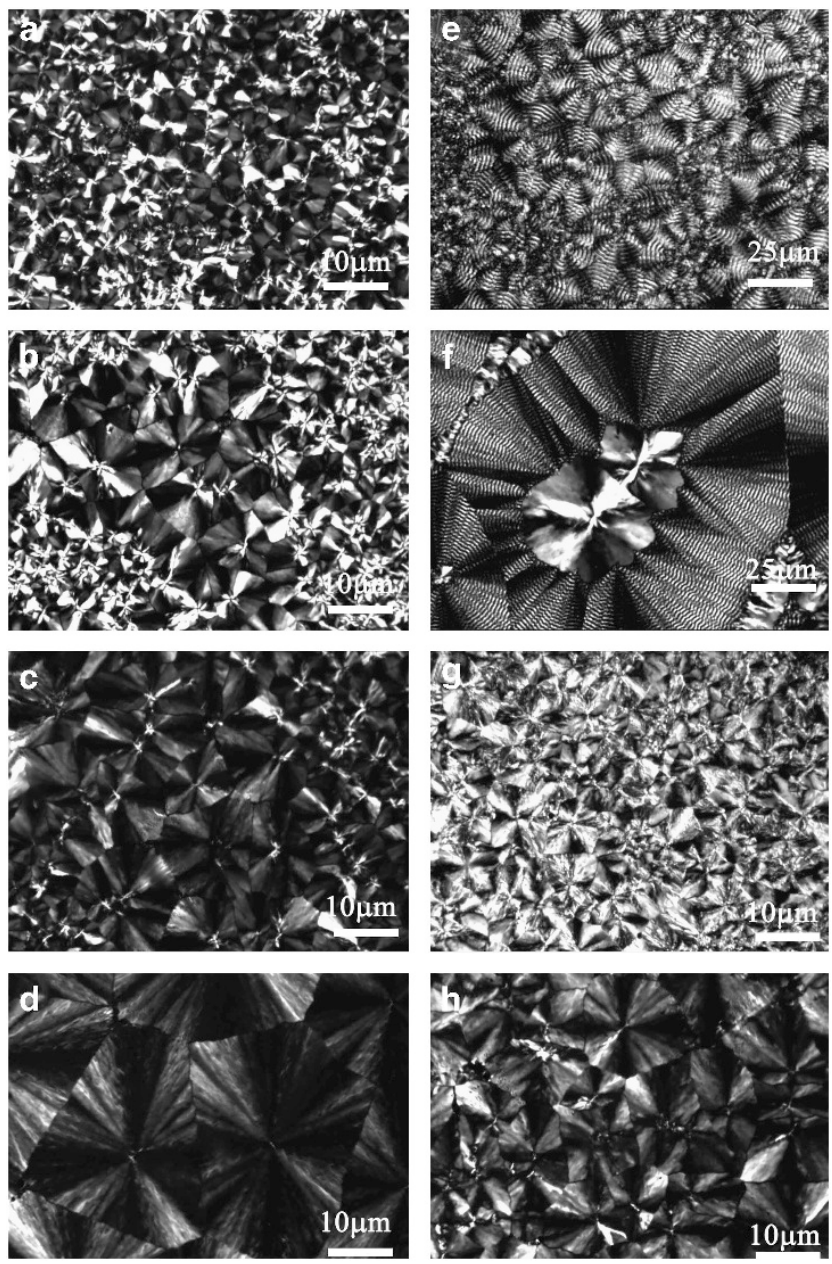

Figure 9 Polarized optical micrographs for neat PBA and PLLA/PBA blend morphologies after isothermal crystallization at different temperatures. The left column shows images for neat PBA: (a) $32^{\circ} \mathrm{C}$, (b) $34^{\circ} \mathrm{C}$, (c) $36^{\circ} \mathrm{C}$ and (d) $38^{\circ} \mathrm{C}$. The right column shows images for PLLA/PBA 20/80: (e) $32^{\circ} \mathrm{C}$, (f) $34{ }^{\circ} \mathrm{C}$, (g) $36^{\circ} \mathrm{C}$ and (h) $38^{\circ} \mathrm{C}$.

lamellar twisting and is influenced by the crystallization temperature and molecular weight. ${ }^{29}$ A neat PBA sample $(\mathrm{Mw}=68000 \mathrm{Da})$ formed banded spherulites at temperatures from 29 to $31^{\circ} \mathrm{C}$ when in the mixed crystal form. ${ }^{30}$ In contrast to neat PBA, the PLLA/PBA blend formed banded spherulites at $34^{\circ} \mathrm{C}$ (mixed crystals) and $32{ }^{\circ} \mathrm{C}$ (only $\beta$ crystals). Such a change may be caused by the presence of solid PLLA, which changes the PBA crystal growth environment. Therefore, blending can provide a valid method for adjusting the morphology of neat PBA.

\section{CONCLUSIONS}

The isothermal crystallization and melting behaviors of PLLA/PBA blends and the neat polymers differ significantly. In the hightemperature region, PBA is melted. The melted PBA chains with high mobility improve the isothermal crystallization rate and enlarge the PLLA spherulite diameter. Furthermore, the addition of PBA decreased the blend equilibrium melting temperature. However, the crystallization mechanism did not change with PBA loading. In the low-temperature region, PLLA is in a glass state. The PBA crystallization rate decreased for the blends because of the rigid PLLA chain. Additionally, PLLA greatly affected the polymorphism structures and 
crystallization morphology of PBA. According to the WAXD results, the PBA in the blends formed $\alpha$ and $\beta$ crystal structures, while neat PBA only formed $\alpha$ crystals at the same temperature. POM demonstrated that banded PBA spherulites formed in blends. These results indicate that the crystallization rate, morphology and crystal structure of neat PLLA and PBA can be modulated via mutual blending.

\section{ACKNOWLEDGEMENTS}

We gratefully acknowledge the financial support of Shandong Province High School Science and Technology Fund Planning Project (No. J13 LA52) and Qingdao Science and Technology program of basic projects

(No. 12-1-4-6-(6)-jch).

1 Rasal, R. M., Janorkar, A. V. \& Hirt, D. E. Poly(lactic acid) modifications. Prog. Polym. Sci. 35, 338-356 (2010).

2 Wang, H. \& Qiu, Z. Crystallization kinetics and morphology of biodegradable poly(L-lactic acid)/graphene oxide nanocomposites: influences of graphene oxide loading and crystallization temperature. Thermochim. Acta 527, 40-46 (2012).

3 Yokohara, T. \& Yamaguchi, M. Structure and properties for biomass-based polyester blend of PLA and PBS. Euro. Polym. J. 44, 677-685 (2008).

4 Wu, D., Lin, D., Zhang, J., Zhou, W., Zhang, M., Zhang, Y., Wang, D. \& Lin, B. Selective Localization of Nanofillers: Effect on morphology and crystallization of PLA/PCL blends. Macromol. Chem. Phys. 212, 613-626 (2011).

5 Focarete, M. L., Ceccorulli, G., Scandola, M. \& Kowalczuk, M. Blends of atactic poly(3hydroxybutyrate) with crystalline polyesters. Macromolecules 31, 8485-8492 (1998).

6 Lin, J. H. \& Woo, E. M. Correlation between interactions, miscibility, and spherulite growth in crystalline/crystalline blends of poly(ethylene oxide) and polyesters. Polymer (Guildf) 47, 6826-6835 (2006).

7 Lu, J., Qiu, Z. \& Yang, W. Fully biodegradable polymer blends Miscibility, crystallization, and mechanical properties. Polymer (Guildf) 48, 4196-4204 (2007).

8 Qiu, Z., Ikehara, T. \& Nishia, T. Miscibility and crystallization in crystalline/crystalline Blends of Poly(butylene succinate)/Poly(ethylene oxide). Polymer (Guildf) 44, 2799-2806 (2003).

9 Wang, H., Schultz, J. M. \& Yan, S. Study of the morphology of Poly(butylene succinate)/Poly(ethylene oxide) blends using hot-stage atomic force microscopy. Polymer (Guildf) 48, 3530-3539 (2007).

10 Qiu, Z., Ikehara, T. \& Nishia, T. Unique morphology of poly(ethylene succinate)/ poly(ethylene oxide) blends. Macromolecules 35, 8251-8254 (2002).

$11 \mathrm{He}, \mathrm{S}$. \& Liu, J. Crystallization and morphology development of binary crystalline poly(ethylene succinate)/poly(ethylene oxide) (PES/PEO) blend with non-isothermal crystallization. Polym. J. 39, 537-542 (2007).
12 Ikehara, T., Kimura, H. \& Qiu, Z. Penetrating spherulitic growth in poly(butylene adipate-co-butylene succinate)/poly(ethylene oxide) blends. Macromolecules $\mathbf{3 8}$, 5104-5108 (2005).

13 Qiu, Z., Yan, C., Lu, J., Yang, W., Ikehara, T. \& Nishia, T. Various crystalline morphology of poly(butylene succinate-co-butylene adipate) in its miscible blends with poly(vinylidene fluoride). J. Phys. Chem. B 111, 2783-2789 (2007).

14 Wang, H., Gan, Z., Schultz, J. M. \& Yan, S. A morphological study of poly(butylene succinate)/poly(butylene adipate) blends with different blend ratios and crystallization processes. Polymer (Guildf) 49, 2342-2353 (2008).

15 Liu, J. \& Jungnickel, B. J. Crystallization kinetical and morphological peculiarities in binary crystalline/crystalline polymer blends. J. Phys. Chem. B 111, 1917-1931 (2007).

16 Zhao, L. \& Gan, Z. Effect of copolymerized butylene terephthalate chains on polymorphism and enzymatic degradation of poly(butylene adipate). Polym. Degrad. Stab. 91, 2429-2436 (2006).

17 Gan, Z., Abe, H. \& Doi, Y. Temperature-induced polymorphic crystals of poly(butylene adipate). Macromol. Chem. Phys. 203, 2369-2374 (2002).

18 Gan, Z., Kuwabara, K., Abe, H., Iwata, T. \& Doi, Y. metastability and transformation of polymorphic crystals in biodegradable poly (butylene adipate). Biomacromolecules $\mathbf{5}$, 371-378 (2004)

19 Wang, N., Zhang, X., Yu, J. \& Fang, J. Study of the properties of plasticized poly(lactic acid) with poly(1,3-butylene adipate). Polym. Polym. Compos. 16, 597-604 (2008).

20 Zhao, L., Peng, X., Liu, X., Wang, Y., Qin, S. \& Zhang, J. Miscibility and morphology of binary crystalline blends of poly(L-lactide) and poly(butylene adipate). Polym. J. 45, 929-937 (2013).

21 Gan, Z., Kuwabara, K., Yamamoto, M., Abe, H. \& Doi, Y. Solid-state structures and thermal properties of aliphatic-aromatic poly(butylene adipate-co-butylene terephthalate) copolyesters. Polym. Degrad. Stab. 83, 289-300 (2004).

22 Avrami, M. Kinetics of phase change. II Transformation-time relations for random distribution of nuclei. J. Chem. Phys 8, 212-224 (1940).

23 Avrami, M. Granulation, phase change, and microstructure kinetics of phase change. III. J. Chem. Phys. 9, 177-184 (1941).

24 Hoffman, J. D., Davis, G. T. \& Lauritzen, J. I. Treatise on Solid State Chemistry, Vol. 3 , Crystalline and Noncrystalline Solids 497-498 (Plenum Press, New York, 1976).

25 Vasanthakumari, R. \& Pennings, A. J. Crystallization kinetics of poly(I-lactic acid). Polymer (Guildf) 24, 175-178 (1983).

26 Taweel, S. H. E. \& Stoll, B. Spherulitic growth rate of blends of polydroxybutyrate(PHB) with oligomeric atactic PHB-diol. J. Macromol. Sci. B 51, 567-579 (2012).

27 Yeh, J., Wu, C., Tsou, C., Chai, W., Chow, J., Huang, C., Chen, K. \& Wu, C. Study on the crystallization, miscibility, morphology, properties of poly(lactic acid)/ poly( $\varepsilon$-caprolactone) blends. Polym. Plast. Technol. 48, 571-578 (2009).

28 Jiang, N., Zhao, L. \& Gan, Z. Influence of nucleating agent on the formation and enzymatic degradation of poly(butylene adipate) polymorphic crystals. Polym. Degrad. Stab. 95, 289-300 (2010)

$29 \mathrm{Liu}$, J., Ye, H., Xu, J. \& Guo, B. Formation of ring-banded spherulites of $\alpha$ and $\beta$ modifications in poly(butylene adipate). Polymer (Guildf) 52, 4619-4630 (2011).

30 Zhao, L., Wang, X., Li, L. \& Gan, Z. Structural analysis of poly(butylene adipate)banded spherulites from their biodegradation behavior. Polymer (Guildf) 48, 6152-6161 (2011). 